\title{
Physical-Mathematical Method Defined of Wave Parameters Gravitation Field
}

\author{
Valentyn Nastasenko
}

\begin{abstract}
The traditional principle of solving the problem of obtained parameters gravitational field associated with of transformation parameters the electromagnetic field on the basis of Maxwell and Lorentz equations. The proposed non-traditional physical-mathematical principle is solving this task by using special physical quantities found by M. Planck in 1900: - Planck's length $l_{p}^{o}$, time $t_{p}^{o}$ and mass $m_{p}^{o}$, the uniqueness of which is that they are obtained on the basis of 3 fundamental physical constants: the speed $\mathrm{c}$ of light in vacuum, the Planck's circular constant $\hbar$ and the gravitational constant $G$, which reduces them to the fundamentals of the Universe. However, it is not clear what real objects of the material world Planck's values can be related to, therefore, they are generally considered to be abstract values, therefore its not used in scientific studies. It is shown in the paper that replacing Planck's circular constant $\hbar$ by Planck's constant $h$ allows one to obtain new values of Planck's length $l_{p}$, time $t_{p}$ and mass $m_{p}$ that are really related to the parameters of the material world. Strict physical regularities were obtained for the based on intercommunication of 3-th fundamental physical constants $\mathbf{c}, \mathbf{h}$ and $G$, that allow to single out wave characteristic $v_{G}$ from $G$ which is identified with the frequency $v_{G}$ of oscillation wave gravitational field. On this base other wave and substance parameters were strictly defined and their numerical values obtained. The solution of given problems is substantiated by well-known physical laws and conformities and not contradiction to modern knowledge about of material world and the Universe on the whole. It is actual for development of physics and other branches of science and technique.
\end{abstract}

Index Terms-Fundamental physical constants, wave parameters of quantization field.

\section{INTRODUCTION}

The paper belongs to the sphere of quantum physics, physics, of waves and physical fields, in particular - to the gravitational fields.

The traditional principle of solving the problem of obtained parameters gravitational field associated with of transformation parameters the electromagnetic field on the basis of Maxwell and Lorentz equations. Many leading scientific schools and scientists of the world are engaged in the search for ways of solving these problems, since they are connected with the global problems of natural science, which have great theoretical and applied significance for the knowledge of the foundations of the material world and the Universe. They are relevant for the development of physics, other natural and technical sciences, in the conditions of a constant need to deepen knowledge about the material world and the Universe as a whole, physical fields and substances

Manuscript received May 17, 2017; revised July 1, 2018

Valentyn Nastasenko is the with Kherson State Maritime Academia, Kherson Ukraine (e-mail: Nastasenko2004@ukr.net). that make up them.

\section{Problem State Analysis And TASK Statement}

Until now, physical parameters of the gravitational field have been understudied, since its only really determinable characteristics is the force $F_{G}$ of the gravitational interaction of physical bodies (1), which follows from Newton's law of gravitation [1], [2]:

$$
F_{G}=G \frac{m_{1} m_{2}}{r^{2}}(N)
$$

where $m_{l}, m_{2}-$ masses $(\mathrm{kg})$ of two point objects situated at the $r(\mathrm{~m})$ - distant between them;

$G$ - gravitational constant [3]:

$$
G=6.67408(31) \cdot 10^{-11} \frac{m^{3}}{k g \cdot s^{2}} .
$$

All other characteristics of the gravitational field are not strictly defined but by analogy with the parameters of electromagnetic field in terms of empiric analogy of the law of Universal gravitation (1) and the Cullen law (3) for the electrostatic interaction of two point bodies [1], [2]:

$$
\left|F_{Q}\right|=\frac{1}{4 \pi \varepsilon_{0}} \cdot \frac{Q_{1} Q_{2}}{r^{2}}(N),
$$

where $\varepsilon_{0}$ - electric constant:

$$
\varepsilon_{0}=8,854187817 \ldots \cdot 10^{-12} \frac{A^{2} s^{4}}{\mathrm{~kg} \cdot \mathrm{m}^{3}},
$$

$Q_{1}, Q_{2}$ - electric charges of two interacting points, $A \cdot s$,

$r$ - distance between interacting points, $m$.

In this case, the empirical analogy with other laws also implies the wave structure of the gravitational field, but it does not give grounds for a rigorous determination of its wave and other real-field characteristics that actually follow from the structure of the given field, and also for the determination of the strict numerical values of these characteristics. In addition, there are contradictions in the effects of attraction and repulsion, since objects with the same electrical charges repel, and those with different charges attract, which is the opposite of gravitational interaction. There are also problems with understanding the processes of transmission of this interaction, since the field structure for the realization of gravity phenomena has not yet been clarified.

It is generally believed that these processes follow from Einstein's general theory of relativity [4], but one curvature of 
space for this is not enough, it is necessary to know what these curved structures are and what they consist of and what their interrelations are. Therefore, the search for solutions to these problems continues. The possibilities of their solution on the basis of superstring theory still have generalized character and also do not contain specific wave parameters. It based of this theory on the principle of deepening transition from level to level of the material world - from the atomic to the subatomic one, to which the elementary particles belong having the properties of substance and field. However, for particles, there are problems in identifying the maximum possible parameters, the minimum of which is usually assumed to be the approximate size and wave parameters of quark its $\approx 10^{-35} \mathrm{~m}$. At the same time, they were not clearly reduced to special physical values discovered by M. Planck in 1900: Planck's length $l_{p}^{o}$, time $t_{p}^{o}$, and mass $m_{p}^{o}[1,2]$, obtained on the basis of strict physical regularities consisting of 3 initial fundamental physical constants: the speed of light in vacuum $c$, the gravitational constant $G$ and the circular Planck's constant $\hbar$, which ensures their specific parameters. This is explained by the fact that before 2000 Planck's values were considered abstract [5], [6].

In the developed theory of gravitational waves, marked by the Nobel Prize in Physics in 2017 [7], there are also no specific wave parameters of the gravitational field, which is explained by the scientific and technical complexity of their determination by traditional ways based on Maxwell and Lorentz equations and by conducting real experiments. Therefore, it is relevant and important to look for other unconventional ways to determine these parameters, to which this paper is dedicated.

For the first time, such an unconventional solution of bud was found in 2014 in works [8], [9], which follows from works [10], [11], but its completeness and quality need to be refined in the framework of new scientific data obtained in recent years, which is the main goal of the performed work.

The scientific novelty of the work being done is:

1) substantiation of a new strict theoretical base for defining wave and substance parameters of gravitational field;

2) finding on this basis the calculated dependencies for determining the wave and real parameters of the gravitational field and finding their numerical values;

3 ) proof of the reliability of the scientific provisions and the results obtained.

\section{The Proposed Solution to THE PROBLEM}

The given task has not only the cognitive but practical significance for studying the laws of gravity from the entire Universe to the subatomic level, which determines the need for new works for its prompt solution

The parameters of the gravitational field found by nontraditional ways in works $[8,9]$, are based on the use of Planck's length $l_{p}^{o}(4)$, time $t_{p}^{o}$ (5) and mass $m_{p}^{o}$ (6) the uniqueness of them is in the fact that they were obtained on the basis of only three initial fundamental physical constants $G(2)$, speed of light in vacuum $c$ (7), and Planck's circular constant $\hbar(9)$ :

$$
\begin{aligned}
& l_{p}^{0}=\sqrt{\frac{\hbar G}{c^{3}}}= \\
& \begin{array}{l}
=\sqrt{\frac{1.054571800 \cdot 10^{-34}(J \cdot s) \cdot 6.67408 \cdot 10^{-11}\left(\frac{\mathrm{m}^{3}}{\mathrm{~kg} \cdot \mathrm{s}^{2}}\right)}{\left[0.299792458 \cdot 10^{9}\left(\frac{\mathrm{m}}{\mathrm{s}}\right)\right]^{3}}}= \\
=1.616229 \cdot 10^{-35}(\mathrm{~m}) .
\end{array} \\
& t_{p}^{0}=\sqrt{\frac{\hbar G}{c^{5}}}= \\
& =\sqrt{\frac{1.054571800 \cdot 10^{-34}(\mathrm{~J} \cdot \mathrm{s}) \cdot 6.67408 \cdot 10^{-11}\left(\frac{\mathrm{m}^{3}}{\mathrm{~kg} \cdot \mathrm{s}^{2}}\right)}{\left[0.299792458 \cdot 10^{9}\left(\frac{\mathrm{m}}{\mathrm{s}}\right)\right]^{5}}}= \\
& =5.39116 \cdot 10^{-44}(s) \text {. } \\
& m_{p}^{0}=\sqrt{\frac{\hbar c}{G}}= \\
& =\sqrt{\frac{1.054571800 \cdot 10^{-34}(J \cdot s) \cdot 0.299792458 \cdot 10^{9}\left(\frac{m}{s}\right)}{6.67408 \cdot 10^{-11}\left(\frac{\mathrm{m}^{3}}{\mathrm{~kg} \cdot \mathrm{s}^{2}}\right)}}= \\
& =2.17647 \cdot 10^{-8}(\mathrm{~kg}) \text {. } \\
& c=0.299792458 \cdot 10^{9} \frac{m}{s}, \\
& h=6.626070040 \cdot 10^{-34}(\mathrm{~J} \cdot \mathrm{s})=6.626070040 \cdot 10^{-34}\left(\frac{\mathrm{kg} \cdot \mathrm{m}^{2}}{\mathrm{~s}}\right) \text {, } \\
& \hbar=\frac{h}{2 \pi}=\frac{6.626070040 \cdot 10^{-34}\left(\frac{\mathrm{kg} \cdot \mathrm{m}^{2}}{\mathrm{~s}}\right)}{2 \cdot 3.14159256}= \\
& =1.054571800 \cdot 10^{-34}\left(\frac{\mathrm{kg} \cdot \mathrm{m}^{2}}{\mathrm{~s}}\right) \text {. }
\end{aligned}
$$

However, it is not clear what real objects of the material world Planck's values $l_{p}^{o}, t_{p}^{o}, m_{p}^{o}$ can be related to, therefore, they are generally considered to be abstract values. For example, comparing them with the dimensions and mass characteristics of an electron gives mutually opposite discrepancies: in size - Planck's length $l_{p}^{o}=1,61623 \cdot 10^{-35} \mathrm{~m}$, they are $10^{20}$ times smaller classical electron radius $r_{\mathrm{e}}=$ $2,8179409 \cdot 10^{-15} \mathrm{~m}$; Planck's mass $m_{p}^{o}=2,17647 \cdot 10^{-8} \mathrm{~kg}-$ they are $10^{23}$ times bigger electron rest mass $\mathrm{m}_{\mathrm{e}}=$ $9,1093897 \cdot 10^{-31} \mathrm{~kg}$.

Within the framework of traditional knowledge of the material world, the use of the values $l_{p}^{o}, t_{p}^{o}, m_{p}^{o}$ in scientific research is limited only by the superdense (singular) period of birth and the Big Bang of the Universe, [12] which results in its materialization and the formation in it of all the original physical fields and substances.

Five scientific discoveries form the basis for a propose of physical-mathematical method defined of wave parameters gravitation field.

The first scientific discovery used in this paper is the substantiation in $[8,9]$ of the reality of the Planck's values of length, time and mass due to their connection with spherical Planck's thickness layers encompassing the parameters of the observable Universe (Figure 1), which makes it possible to 
distribute the mass $m_{p}^{o}$ over the entire spherical layer.

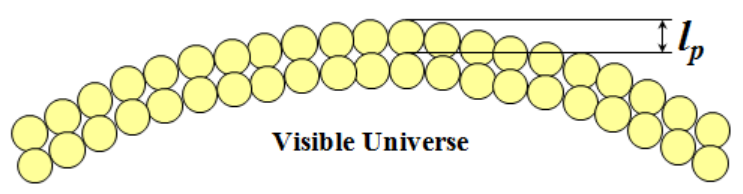

Fig. 1. Relationship of Planck's parameters with the parameters of the sphere of the observable Universe.

It is therefore recognized that it is possible to use them in scientific research.

The second scientific discovery used in this paper is the justification of the parameters of the minimum quantum of the Universe.

In paper [5], [6], the reality of Planck's values $l_{p}^{o}, t_{p}^{o}, m_{p}^{o}$ as parameters of Planck's layer having the thickness of $l_{p}^{o}$, which enfold the whole space of the spherical Universe by layered spheres, is proved. Since they belong to a deeper level of the material world than the subatomic one, where the laws of quantum mechanics operate, quantization is also possible for them, incl. with other physical quantities of macro- and microlevels, which makes it possible to use of International System (SI) units for analysis: of 1 meter (m), 1 second (s) and 1 kilogram (kg) [13]. But their multiplicity of $n$, as the main sign of quantization was not found (10)...(12):

$$
\begin{aligned}
& n_{l}=\frac{1(\mathrm{~m})}{l_{p}^{o}}=\frac{1(\mathrm{~m})}{1.616229 ? 0^{-35}(\mathrm{~m})}=6.18724 ? 0^{34}, \\
& n_{t}=\frac{1(\mathrm{~s})}{t_{p}^{o}}=\frac{1(\mathrm{~s})}{5.39116 \cdot 10^{-44}(\mathrm{~s})}=1.85489 ? 0^{43}, \\
& n_{m}=\frac{1(\mathrm{~kg})}{m_{p}^{o}}=\frac{1(\mathrm{~kg})}{2.176470 \cdot 10^{-8}(\mathrm{~kg})}=4.59460 ? 0^{7} .
\end{aligned}
$$

The analysis performed in [14] led to the understanding of the convention of introducing Planck's constant $\hbar$ (9) obtained by dividing Planck's constant $h$ (8) recommended by CODATA [3] by $2 \pi$ number, which reduces Planck's values $l_{p}^{o}, t_{p}^{o}, m_{p}^{o}$ found on its basis to internal parameters (gravitational radius) of the minimum space quantum of the Universe. Therefore, in paper [14] by analogy with $l_{p}^{o}, t_{p}^{o}, m_{p}^{o}$, natural or external Planck's values $l_{p}, t_{p}, m_{p}$ (13)...(16) were determined on the basis of the initial value of Planck's constant $h$ (8) characterizing the parameters of the minimum quantum of space of the Universe:

$$
\begin{aligned}
& l_{p}=\sqrt{\frac{h G}{c^{3}}=} \\
& =\frac{6.62607004 \cdot 10^{-34}\left(\frac{\mathrm{kg} \cdot \mathrm{m}^{2}}{\mathrm{~s}}\right) \cdot 6.67408 \cdot 10^{-11}\left(\frac{\mathrm{m}^{3}}{\mathrm{~kg} \cdot \mathrm{s}^{2}}\right)}{\left[0.299792458 \cdot 10^{9}\left(\frac{\mathrm{m}}{\mathrm{s}}\right)\right]^{3}}
\end{aligned}
$$

$$
\begin{aligned}
& t_{p}=\sqrt{\frac{h G}{c^{5}}=} \\
& =\sqrt{\frac{6.62607004 \cdot 10^{-34}\left(\frac{\mathrm{kg} \cdot \mathrm{m}^{2}}{\mathrm{~s}}\right) \cdot 6.67408 \cdot 10^{-11}\left(\frac{\mathrm{m}^{3}}{\mathrm{~kg} \cdot \mathrm{s}^{2}}\right)}{\left[0.299792458 \cdot 10^{9}\left(\frac{\mathrm{m}}{\mathrm{s}}\right)\right]^{5}}}= \\
& =13.5136 \cdot 10^{-44}(\mathrm{~s}) .
\end{aligned}
$$

$$
\begin{aligned}
& m_{p}=\sqrt{\frac{h c}{G}}= \\
& =\frac{6.62607004 \cdot 10^{-34}\left(\frac{\mathrm{kg} \cdot \mathrm{m}^{2}}{\mathrm{~s}}\right) \cdot 0.299792458 \cdot 10^{9}\left(\frac{\mathrm{m}}{\mathrm{s}}\right)}{6.67408 \cdot 10^{-11}\left(\frac{\mathrm{m}^{3}}{\mathrm{~kg} \cdot \mathrm{s}^{2}}\right)}= \\
& =5.45560 \cdot 10^{-8}(\mathrm{~kg}) .
\end{aligned}
$$

Their analysis values (13)...(15) for quantization with a 1 $\mathrm{m}, 1 \mathrm{~s}$ and $1 \mathrm{~kg}$ yielded the followings results (16)...(18):

$$
\begin{aligned}
& n_{l}=\frac{1(\mathrm{~m})}{l_{p}}=\frac{1(\mathrm{~m})}{4.05128 ? 0^{-35}(\mathrm{~m})}=2,46836 ? 0^{34}, \\
& n_{t}=\frac{1(\mathrm{~s})}{t_{p}}=\frac{1(\mathrm{~s})}{13.5136 \cdot 10^{-44}(\mathrm{~s})}=7.39995 ? 0^{43}, \\
& n_{m}=\frac{1(\mathrm{~kg})}{m_{p}}=\frac{1(\mathrm{~kg})}{5.45560 \cdot 10^{-8}(\mathrm{~kg})}=1,83298 ? 0^{7} .
\end{aligned}
$$

Thus, the uniqueness of quantization of the values of time (17) was found within the accuracy of the calculated value of $t_{p}$, which has 6 characters, in accordance with the accuracy of the gravitational constant $G(2)$.

In that way the uniqueness of time quantization 1 second and $t_{p}(17)$, was revealed which coincides within the limits of accuracy of calculation magnitude $t_{p}$, making 6 characters, its limited accuracy gravitation constant $G(2)$. However for other magnitudes: - a $1 \mathrm{~m}$ and $1 \mathrm{~kg}$ the coincidences were not revealed, that demands an additional analysis of these values.

This can be explained by the fact that initially [13] the values of $1 \mathrm{~m}$ and $1 \mathrm{~kg}$ [13] were chosen randomly: $1 \mathrm{~m}$ to be equal $1 / 10000000$ share $1 / 4$ of Parisian meridian, $1 \mathrm{~kg}$ to be equal the mass of distilled water, filling a cube vessel with the length of a side 0,1 meter. The value of $1 \mathrm{~s}$ was associated with the daily is strictly rotation of the Earth in the Solar orbit, the parameters of which are determined by gravitational interaction. In this case, there is a reason to believe that quantizing the value 1 with Planck's time $t_{p}$ is not a coincidence. In is also necessary to take into account that numerical value (17) is Planck's frequency $v_{p}$ (19), [15]:

$$
v_{p}=\frac{1}{t_{p}}=\frac{1}{13,5136 \cdot 10^{-44}(c)}=0,0739996 \cdot 10^{44}\left(c^{-1}\right)
$$


This gives the parameters (17), (19) a new physical meaning. However, the dependence (14) is not physically rigorous, which requires the elimination of this shortcoming.

The third scientific discovery used in this paper is the possibility of obtaining the fundamental physical constants $c$, $G, h$ within their dimensionality on the basis of the Planck's parameters $l_{p}, t_{p}, m_{p}$ [15]. For example, the gravitational constant $G$ can be expressed by the dependence (20):

$$
\begin{aligned}
& G\left(\frac{m^{3}}{k g \cdot s^{2}}\right)=\frac{l_{p}^{3}}{m_{p} t_{p}^{2}}= \\
& =\frac{\left[4.05128 \cdot 10^{-35}(\mathrm{~m})\right]^{3}}{5.45560 \cdot 10^{-8}(\mathrm{~kg}) \cdot\left[13.5136 \cdot 10^{-44}(\mathrm{~s})\right]^{2}}= \\
& =6.67409 \cdot 10^{-11}\left(\frac{\mathrm{m}^{3}}{\mathrm{~kg} \cdot \mathrm{s}^{2}}\right) .
\end{aligned}
$$

The fourth scientific discovery used in this work is the justification of the real value of the frequency of oscillation of the gravitational field.

On the basis of rigorous physicals dependences (14) and (20) a new rigorous dependence (21) was obtained in $[11,16$, 17] for determining the gravitational constant value:

$$
\begin{aligned}
& G=\frac{t_{p}^{2} c_{p}^{2}}{h}= \\
& =\frac{\left[13.5136 \cdot 10^{-44}(s)\right]^{2}\left[0.299792458 \cdot 10^{9}\left(\frac{m}{s}\right)\right]^{5}}{6.626070040 \cdot 10^{-34}\left(\frac{\mathrm{kg} \cdot \mathrm{m}^{2}}{\mathrm{~s}}\right)}= \\
& =6.67405 \cdot 10^{-11}\left(\frac{\mathrm{m}^{3}}{\mathrm{~kg} \cdot \mathrm{s}^{2}}\right) .
\end{aligned}
$$

Transformer this dependences (21) and used dependences (19) was found new string for determining the gravitational constant value $G$ (22):

$$
G=\frac{t_{p}{ }^{2} c^{5}}{h}=\frac{c^{5}}{v_{p}{ }^{2} h}=\frac{c^{5}}{v_{G}{ }^{2} h} .
$$

According to the strict physical dependence (22), obtained on the basis of fundamental physical constants: the frequency $v_{G}$ was determined, having the Plank's level $v_{p}$ :

$v_{G}=v_{p}=\sqrt{\frac{c^{5}}{G h}}=$

$$
\begin{aligned}
& =\sqrt{\frac{\left[0.299792458 \cdot 10^{9}\left(\frac{\mathrm{m}}{\mathrm{s}}\right)\right]^{5}}{6.67405 \cdot 10^{-11}\left(\frac{\mathrm{m}^{3}}{\mathrm{~kg} \cdot \mathrm{s}^{2}}\right) \cdot 6.626070040 \cdot 10^{-34}\left(\frac{\mathrm{kg} \cdot \mathrm{m}^{2}}{\mathrm{~s}}\right)}}= \\
& =7.39995 \cdot 10^{42}\left(\mathrm{~s}^{-1}\right) .
\end{aligned}
$$

This frequency (23) enters into a strict physical dependence for the determination of $G$ (24)

$$
\begin{aligned}
& G=\frac{c^{5}}{v_{G}^{2} h}= \\
& =\frac{\left[0.299792458 \cdot 10^{9}\left(\frac{\mathrm{m}}{\mathrm{s}}\right)\right]^{5}}{\left[7.39995 \cdot 10^{42}\left(\mathrm{~s}^{-1}\right)\right]^{2} \cdot 6.626070040 \cdot 10^{-34}\left(\frac{\mathrm{kg} \cdot \mathrm{m}^{2}}{\mathrm{~s}}\right)}= \\
& =6.67408 \cdot 10^{-11}\left(\frac{\mathrm{m}^{3}}{\mathrm{~kg} \cdot \mathrm{s}^{2}}\right) .
\end{aligned}
$$

Since the constant $G$ is a constituent element in the Newton's law of gravity for determining the gravitational forces in the Universe (1), we can therefore strictly state that $v_{G}$ is the frequency of this field. This reveals new possibilities for the knowledge of the foundations of the material world.

\section{NeW Possibility OF DETERMining THE GRAVITATION FIELD PARAMETERS}

The fifth scientific discovery used in this paper, is a strict definition of the parameters of the gravitational field that follow from its frequency of oscillation $v_{G}$.

On the basis of the found value of the frequency of oscillation $v_{G}=v_{p}(23)$, it is possible to determine all other wave parameters of the gravitational field, including the following basic ones:

1. The period $T_{G}$ of oscillation wave

$$
\begin{array}{r}
T_{G}=\frac{1}{v_{G}}=\frac{1}{7.39995 \cdot 10^{42}\left(s^{-1}\right)}=1.35136 \cdot 10^{-43}(s)= \\
=t_{p}=\sqrt{\frac{h G}{c^{5}}}=1.35136 \cdot 10^{-43}(\mathrm{~s}) .
\end{array}
$$

2. The wavelength $\lambda_{G}$ of the oscillation:

$$
\begin{gathered}
\lambda_{G}=\frac{c}{v_{G}}=\frac{0.299792458 \cdot 10^{9}\left(\frac{m}{s}\right)}{7.39995 \cdot 10^{42}\left(s^{-1}\right)}= \\
=4.05128 \cdot 10^{-35}(\mathrm{~m})=l_{p}=\sqrt{\frac{h G}{c^{3}}}= \\
=4.05126 \cdot 10^{-35}(\mathrm{~m}) .
\end{gathered}
$$

3. The amplitude $A_{G}$ of the oscillations, which within the limits of the restriction of all interactions to the speed of light $c$ at the frequency of oscillation period $T_{G}$, actually coincides with the wavelength $\lambda_{G}$ :

4.

$$
\begin{gathered}
A_{G}=\lambda_{G}=4.05128 \cdot 10^{-35}(\mathrm{~m})= \\
=l_{p}=\sqrt{\frac{h G}{c^{3}}}=4.05126 \cdot 10^{-35}(\mathrm{~m}) .
\end{gathered}
$$

5. Wave energy $E_{G}$ of the gravitational field:

$$
\begin{gathered}
E_{G}=h v_{G}=6.626070040 \cdot 10^{-34}(J \cdot s) \cdot 7.39995 \cdot 10^{42}\left(s^{-1}\right) \\
=4.90328 \cdot 10^{9}(J)=E_{p}=\sqrt{\frac{h c^{5}}{G}=}
\end{gathered}
$$

$$
=\sqrt{\frac{6.626070040 \cdot 10^{-34}(\mathrm{~J} \cdot \mathrm{s})\left[0.299792458 \cdot 10^{9}\left(\frac{\mathrm{m}}{\mathrm{s}}\right)\right]^{5}}{6.67405 \cdot 10^{-11}\left(\frac{\mathrm{m}^{3}}{\mathrm{~kg} \cdot \mathrm{s}^{2}}\right)}}=
$$

6. Mass equivalent $m_{G}$ of the wave energy $E_{G}$ of the gravitational field, or its energy mass, which in the framework of Einstein's law $E=m c^{2}$ on the connection of total energy and mass [1], [2], amounts to: 


$$
\begin{aligned}
& m_{G}=\frac{E_{G}}{c^{2}}=\frac{h v_{G}}{c^{2}}= \\
& =\frac{6.626070040 \cdot 10^{-34}\left(\frac{\mathrm{kg} \cdot \mathrm{m}^{2}}{\mathrm{~s}}\right) \cdot 7.39995 \cdot 10^{42}\left(\mathrm{~s}^{-1}\right)}{\left[0.299792458 \cdot 10^{9}\left(\frac{\mathrm{m}}{\mathrm{s}}\right)\right]^{2}}= \\
& =5.45564 \cdot 10^{-8}(\mathrm{~kg})= \\
& =m_{p}=\sqrt{\frac{h c}{G}}=5.45564 \cdot 10^{-8}(\mathrm{~kg}) .
\end{aligned}
$$

The relationship between the mass (29) and the wave parameters of the gravitational field is an additional proof of the validity of all the scientific propositions advanced above, since without the presence of mass, the gravitational field does not exist. In this case, the energy values (28) and the equivalent of the energy mass (29) are connected with the entire front of the spherical wave of the gravitational field, which is confirmed by the first scientific discovery made in [5], [6].

Reliability of scientific statements put forward above field (23)...(28) and substance 29) parameters of gravitational field obtained on their basic is confirmed by:

1) size-mass parameters of gravitational field by the low of Heisenberg's law of in definability of imputes $(31)[1,2]$ for speed $v_{G}$ wave gravitational field (30), which within the accuracy of the values included in it tends to the speed of light $c(7)$ :

$$
\begin{gathered}
v_{G}=\frac{\lambda_{G}}{T_{G}}=\frac{4.05128 \cdot 10^{-35}(\mathrm{~m})}{13.5136 \cdot 10^{-44}(\mathrm{~s})}=0.2997928 \cdot 10^{9}\left(\frac{\mathrm{m}}{\mathrm{s}}\right) \\
\rightarrow c=0.299792458 \cdot 10^{9}\left(\frac{\mathrm{m}}{\mathrm{s}}\right) \cdot(30) \\
m_{G} v_{G}=\frac{h}{\lambda_{G}}=5.45560 \cdot 10^{-8}(\mathrm{~kg}) \cdot 0.299792458 \cdot 10^{9}\left(\frac{\mathrm{m}}{\mathrm{s}}\right)= \\
=\frac{\left.6.62607004 \cdot 10^{-34} \mathrm{~J} \cdot \mathrm{s}\right)}{4.05128 \cdot 10^{-35}(\mathrm{~m})}=16.35549\left(\frac{\mathrm{kg} \cdot \mathrm{m}}{\mathrm{s}}\right)
\end{gathered}
$$

2) frequency-mass parameters of gravitational field by de Broil [1], [2] wave (32) if Plank's energy $E_{G}=h v_{G}$ of gravitational field radiation (28) and by Einstein's law $E_{G}=$ $=m_{G} c^{2}[1]$, [2] of mass its component substance obtained of the connection of mass and energy:

$$
\begin{aligned}
& v_{G}=\frac{E_{G}}{h}=\frac{m_{G} c^{2}}{h}=7.39995 \cdot 10^{42}\left(\mathrm{~s}^{-1}\right)= \\
& =\frac{5.45560 \cdot 10^{-8}(\mathrm{~kg}) \cdot\left[0.299792458 \cdot 10^{9}\left(\frac{\mathrm{m}}{\mathrm{s}}\right)\right]^{2}}{6.626070040 \cdot 10^{-34}\left(\frac{\mathrm{kg} \cdot \mathrm{m}^{2}}{\mathrm{~s}}\right)}\left(\mathrm{s}^{-1}\right) .
\end{aligned}
$$

Values (30)...(32) obtained on the basis of repeatedly approved reliably physical laws allow to maintain that field structure with Planck's mass (29) and wave parameters (23)...(28) of minimum possible in the Universe $[5,13]$ length of the wave $\lambda_{G}$ and maximum possible wave oscillation $v_{G}$ is gravitational field, quant of space composing it having sizes (13) being domains of the environment of gravitational field which because of their very small size-mass parameters can be named gravitino, by analogy with neutrino, its help talking this parameters. On this base of allows determining all other parameters gravitational field.
New fundamental physical constant of frequency of oscillation $v_{G}$ found on the basis of fundamental physical constant $c, G, h$, therefore $v_{G}$ fexpands the notion of the material world and provides the possibility of analytical refinement parameters of gravitational field. At the same time, previously unknown objectively existing laws and regularities of the material world are established, which have been proved in [5], [6], [8]-[12], [14]-[17] and in this paper for the first time, therefore they can be qualified as scientific discoveries [18].

The results of physical-mathematical method defined of wave parameters gravitation field were presented and recommended for publication on 2-th International Conference on Quantum Physics and Quantum Technology in Berlin, Germany [16] and 3-th International Conference on Theoretical and Condensed Matter Physics in New York, USA [17].

On the basis of the found parameters of the gravitational field, it is possible to unite it with the electromagnetic field, which restricts the limits of this uniting only by the frequency $v_{G}[16],[17]$.

\section{General CONCLUSIONS}

1. The possibility of analytical determination of wave and real-valued parameters of the gravitational field is found on the basis of strict physical dependences, which are formed by fundamental physical constants: Planck's constant $h$, velocity of light in vacuum c, gravitational constant $G$, which confirms their reliability.

2. On the basis of strictly reliable physical laws, a new fundamental physical constant is frequency of oscillation, $v_{G}$ is rigorously justified, which characterizes the frequency of oscillation of the gravitational field of the Universe; it make strictly connecting the fundamental physical constants $c, h, G$.

3. A strictly formalized method for determining the real parameters of the frequency $v_{G}$ of the wave oscillations of the gravitational field is found, and on its basis the method for determining all other values of its wave and physical parameters.

4. The obtained values of the wave and dimensional-mass parameters of the gravitational field are tested for accuracy by using them in various other calculations, which give a previously known high-precision result.

5. The proposed new values of the fundamental physical constants $v_{G}$, and others parameters gravitation field are obtained on the strictly basis of reliable physical laws and do not contradict its, and therefore can be used in scientific research.

6 . The received data and the proposed fundamentally new of physical-mathematical method defined of wave parameters gravitation field can be qualified as scientific discoveries.

\section{REFERENCES}

[1] D. V. Alekseev, A. M. Bonch-Bruevich, and A. S. Voronov-Romanov et al., Phizicheskij encyclopedicheskij slovar. Pod red. A. M.Prohorov (Ed.). Moskva : Sov. Encyclopedia.-S. 136, 1983.

[2] A. F. Belov, V. G. Voskobounikov et al., Politechnicheskij slovar/Red. col.: A.Yu. Ishlinskij (gl. red.) i dr, -3-e izd., pererab. i dop. -M.: Sov. Encyclopedia, 1989. 
[3] CODATA Internationally recommended values of the Fundamental Physical Constants

[4] B. Parker and M. Ejnstejna, V poiskah edinoj teorii stroenija Vselennoj. - SPb.: Amfora, 2000.

[5] V. A. Nastasenko, Etalon massu v elementah kvantovoj phiziki: Mashinostroense i technosphera na rubeje XXI v. Sbornik trudov VI Megdunarodnoj nauchno-technicheskoj. konferencii $v$ Sevastopole, 2000

[6] V. A. Nastasenko, "Ayaliz granuchno mojluvyh csharuvatuh ctryktur: Fizika i himija tverdogo tila".

[7] Nobelprize. https://www.nobelprize.org/nobel_prizes/physics/laureates/2017/press .html

[8] V. A. Nastasenko, "Strogoe opredelenie volnovihkh parametrov gravitacionnogo polya i objhedinenie gravitacionnogo i ehlektromagnitnogo poleyj: Suchasni informaciyjni ta innovaciyjni tekhnologii na transporti," Mizhnarodna naukovo-praktichna konferencia, Kherson, KhDMA, 2014.

[9] V. A. Nastasenko, Novue osnovu dlja strogogo opredelenia volnovihkh parametrov gravitacionnogo polya i objhedinenie gravitacionnogo $i$ ehlektromagnitnogo poleyj: Naukoviyj visnik KhDMA: naukoviyj zhurnal. Kherson, 2014.

[10] V. A. Nastasenko, Novue vozmojnosti analitihteskogo utochneniya gravitacionnoyj postoyannoyj: Naukoviyj visnik KhNTU: naukoviyj zhurnal. Kherson, 2011.

[11] V. A. Nastasenko, O vozmozhnosti utochneniya znacheniya gravitacionnoyj postoyannoyj raschetnihm putem: Vihsokoproizvoditeljnihe vihchisliteljnihe sistemih 2013, Kiev, 2013

[12] S. Dj. Boljshoyj Vzruv. I. D. Novikova (Ed.). Moskva : Mir. - 391, 1982.
[13] G. D. Byrdyn, Spravochnik po Mejdynarodnoj sisteme edinic. - M. Izd-vo standartov, 1972.

[14] V. A. Nastasenko, Obgruntuvannya parametriv minimaljnogo kvanta prostoru Vsesvitu: Naukoviyj visnik KhDMA: naukoviyj zhurnal. Kherson, 2012.

[15] V. A. Nastasenko, Otkrutie predelno vozmojnuh volnovuh parametrov: Theoria and tehnica peredachi, priema i pererabotki informacii. 10-ja jubilejnaja Megdunarodnaja conferencia. Kharkov : KhNURE, 2004.

[16] V. A. Nastasenko, "New principles of solving the problem of combining the gravitational and electromagnetic fields," in Proc. International Conference on Quantum Physics and Quantum Technology, 2017.

[17] V. A. Nastasenko, "On the possibility of refining the gravitational constant and solving the task of integrating the gravitational and electromagnetic fields," in Proc. International Conference on Theoretical and Condensed Matter Physics., 2017.

[18] Civiljniyj kodeks Ukrainu, Zakonu Ukrainu. Kyiv : Shkola, 2003.

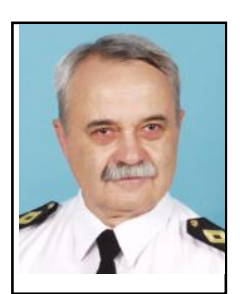

Valentiyn Alekseevitch Nastasenko is the Kherson State Maritime Academy Ukraine, faculties Electrical engineering and electronics, the department of transport technologies. Professor of the department of transport technologies candidate of Dr. technical sciences.

A sphere of scientific interests includes quantum physics, the theory of gravitation, fundamentals of the material world and the birth of the Universe, the author of more than 50 scientific works in these spheres. 